\title{
Las fronteras del hombre y la investigación educacional ${ }^{1}$
}

PABLO LATAPÍ SARRE ${ }^{2}$

Centro de Estudios sobre la Universidad/UNAM

Distinguidos miembros del presidium;

Colegas investigadores;

Maestras, maestros, estudiantes;

Señoras y señores:

D

n esta clara y amable ciudad de Mérida nos reunimos por cuarta vez los investigadores de la educación, en nuestro Congreso Nacional, para reflexionar sobre nuestras tareas y nuestros retos.

Al filo del siglo y del milenio nos sentimos sobrecogidos por una mezcla de incertidumbre y de esperanza; sea que miremos hacia el escenario planetario, sea que contemplemos el nacional, quedamos perplejos ante los profundos cambios que impulsan al mundo; nos preocupa su ambivalencia y descontrolada impetuosidad; pero nos preocupa más nuestra aparente impotencia y, en el fondo, la profunda ignorancia sobre lo que somos.

Los cambios producidos, no en el milenio, sino en el siglo que termina equivalen -podría decirse- a los que provocó alguna gla-

1. Conferencia inaugural del IV Congreso Nacional de Imestigación Educativa, celebrado en la ciudad de Mérida, Yuc., los días 29, 30 y 31 de octubre de 1997.

2. El Dr. Pablo Latapí es investigador del Centro de Estudios sobre la Universidad de la unam y miembro del Consejo Académico del Doctorado Interinstitucional en Educación, programa coordinado por la UAA. 
ciación; quien compare cómo vivían los hombres en 1900 y cómo viven en 1997 estará tentado a concluir que se trata de una especie diferente; $\tan$ diversas son las condiciones de vida, las maneras como nos transportamos y comunicamos, como hacemos ciencia y organizamos la producción; son abismales las diferencias, por ejemplo, en las técnicas quirúrgicas para operar los ojos o en los medios para explorar el universo astronómico. Son cambios, además, no sólo materiales, sino psicológicos, sociales y culturales: se han transformado las nociones fundamentales de espacio y de tiempo, de materia, energía y velocidad, el horizonte de lo posiblé, la relación de los individuos entre sí y la conciencia de nosotros mismos; somos ya otros.

Nos encontramos en un momento de enorme plasticidad del mundo y de enorme plasticidad de nuestra especie. El mundo nos parece ahora un proyecto inacabado, extendido en el tiempo, una realidad dinámica y dispareja, mezcla de orden y de caos, vertiginosamente abierta hacia el futuro. No cumple un designio, sino lo busca, no se ajusta a las leyes invariables, sino las crea y recrea con una sabiduría que parece gozarse en la indeterminación. En el orden material los astrónomos atisban las inauditas sorpresas del cosmos; en el de los seres vivos nos sobrecoge su aleatoriedad: uno se pregunta si cada árbol crece hasta su plenitud o estuvo sujeto a mil circunstancias que mermaron su fronda y produjeron su muerte prematura; ningún arroyo es perfecto, ninguna ola es idéntica a la anterior.

En la vida humana esta indeterminación nos estremece. Cada mujer y cada hombre realizan sólo una de sus posibilidades, las demás quedan para siempre disueltas en la nada. Todos los días nacen y mueren en nosotros millones de células y, a la par, innumerables proyectos y anhelos que nunca serán realizados. Vida y muerte se entrelazan en cada instante humano; nuestro conocimiento es tentativo, al igual que nuestro deseo; ambos están abiertos a nuevas realizaciones y en su finitud llevan su frustración. La belleza que 
nos es dado disfrutar es por definición finita; cada crepúsculo puede ser superado y no hay poema que no sea nuevo al releerse. La vida es frágil, siempre aleatoria; magnífica pero fugaz y dispensable; la muerte le es consustancial.

Tuvimos principio; hubo un momento en que se irguió el "homo sapiens" y tomó conciencia de sí mismo; y tendremos un fin, cuando lleguen a su ocaso las frágiles condiciones que hacen posible la vida, mucho antes de que se extinga el sol dentro de cinco millones de años.

Hoy estamos asistiendo no al fin de la historia, sino a un nuevo principio, más vigoroso y aventurado. Los seres humanos seguimos siendo especie inacabada, "animal no fijado" (Nietzsche), embrión quizás de un ser futuro que lucha por abrirse paso en cada una de nuestras equivocaciones, violencias y desproporcionadas ambiciones. Continuaremos corriendo tras nuestros sueños y experimentando los riesgos de nuestra libertad -que son formas de decir que, en medio de la perplejidad, seguimos teniendo esperanza.

¡Hermoso escenario para quienes nos dedicamos a pensar sobre la educación! ¡Apasionante tarea la de asomarnos a todas las ciencias para recoger lo que vislumbran sobre el futuro del hombre y sobre sus potencialidades de aprendizaje! Para esto estamos hoy aquí.

Quisiera sugerir algunas reflexiones sobre lo que pudiéramos llamar las fronteras de la especie, explorando tres dimensiones que nos son consustanciales: el pensamiento, la belleza y la responsabilidad ética, tratando de recoger en cada una de ellas, algunas grandes preguntas para la investigación educativa. Será sólo un esbożo, una insinuación de temas que requerirían tratamientos más profundos y detenidos.

\section{El PENSAMIENTO}

Un día surgió Pallas Athenea de la cabeza de Zeus; un día empezamos a ser hombres porque empezamos a pensar. Ya no conocía- 
mos simplemente el mundo exterior para orientarnos en él, sino empezamos a elaborar representaciones originales y sobre todo a adentrarnos en el pensamiento reflejo y, con ello, a tener conciencia de nosotros mismos. Fue la gran apertura de la especie hacia el futuro.

Imbricado en el pensamiento nació el lenguaje, que revela una capacidad formidable: la capacidad simbólica. Atribuimos a un sonido, a un gesto, a una actitud un significado; lo convertimos en signo; desarrollamos símbolos y códigos para comunicarnos y para entendernos a nosotros mismos. Esto multiplicó enormemente la capacidad de conocimiento. El hombre, animal que habla, animal de símbolos, adquirió así la posibilidad de crear cultura. Porque con el lenguaje la palabra permanece disponible para utilizarse como recurso continuo y flexible; la palabra crea comunidad, lazos de interés y de entendimiento; la palabra acumula conocimientos y experiencias y da origen a una tradición; la palabra se constituye en herramienta de progreso y de perfeccionamiento.

Somos ahora seres cruzados por el lenguaje. Lenguaje y pensamiento van de la mano; con razón se dice que no escribimos lo que pensamos sino que escribimos para pensar. Hablamos pensando y pensamos hablando. La palabra interviene en la conquista de cada nuevo pensamiento, y éste encuentra rigor y secuencia en el discurso verbal en que inevitablemente se sustenta; logos es a la vez palabra e idea.

Más tarde, con el lenguaje escrito empezó la memoria colectiva, empezó la historia. Travesura genial o juego necesario, la escritura comenzó a documentar la experiencia y a entregarla a las siguientes generaciones. La estela conmemoró hechos que así vencieron al olvido; la inscripción sobre la tumba dio inmortalidad al rey muerto; el libro sagrado consignó mitos fundadores, leyes e identidades. Escribas y cronistas, monjes copistas, trovadores y científicos guardaron por escrito el saber acumulado. Luego llegó el libro impreso, y con él se gestaron fenómenos incalculables: la alfabetización universal, el libre examen y la difusión del conocimiento. Por el libro aumentó 
el sentido crítico, la exigencia ante el poderoso, el rigor de la ciencia moderna, la conciencia de la universalidad humana y otros muchos fenómenos que nos han hecho lo que hoy somos.

En épocas más recientes la apertura cognoscitiva experimentó novedades apasionantes; desgarramos velos que abrieron horizontes insospechados a la razón. El camino lo anunciaron Jan van Eyck y Nicolás de Cusa; lo descubrió -a costa de su vida- Giordano Bruno, el "trovador de la infinitud", quien proclamó "il eroico furore", la capacidad infinita de la razón, y afirmó con escándalo que los hombres somos capaces de adquirir una conciencia cósmica. El argumentaba que la fuerza que confirma todas las cosas finitas crea incansablemente nuevas formas; y que en la totalidad del universo lo posible y lo real tienen que coincidir plenamente, porque el universo tiene que recoger todas las posibilidades para ser perfecto. Además, proclamó la "visión desiderativa" del mundo y -lo que se interpretó como locura y blasfemia- la validez y preeminencia de explorar con el deseo lo desconocido.

La apertura cognoscitiva la ahondó después Copérnico, descubriendo un nuevo espacio, desgarrado de la pequeña Tierra, en el cual tanto ésta como el mismo sol desaparecen como centro; queda la esfera infinita cuyo centro está en todas las partes... Kepler le sucedió, con nuevas explicaciones astronómicas, y después vino Newton, quien introdujo un espacio eterno y un tiempo que se extiende hacia el infinito. Siguió Spinoza con su panteísmo matemático y, más tarde, ya en este siglo, sobrevino la revolución cognoscitiva de la física atómica y la relatividad. Hoy sabemos que nuestra observación modifica la realidad observada, que el espacio es curvo y el tiempo una cuarta dimensión, que masa y energía son convertibles y corpúsculo y onda intercambiables; y la teoría cuántica, a la vez que reduce las pretensiones de nuestra razón de conocer la realidad como es, ha devuelto paradójicamente a la mente su función de cocreadora de esa misteriosa realidad. Hemos pasado de creernos una partícula diminuta en la inmensidad de las galaxias, a la 
conciencia de que somos los actores principales en el drama universal del cosmos3.

En paralelo con esta apertura del conocimiento respecto al mundo material han marchado los avances respecto a las ciencias de la vida, a las ciencias sociales y humanas, a la realidad oculta de nuestro inconsciente. Lo que explica la creatividad científica, conviene recordarlo, ha sido la capacidad de algunos hombres para aceptar tentativamente el absurdo, lo no convencional, lo heterodoxo; el genio es el que se atreve a imaginar lo insensato y a navegar por los márgenes prohibidost.

Hoy el hombre está perplejo ante las paradojas que le plantea su pequeñez y el avance del conocimiento; se pregunta cómo es posible que siendo parte de la naturaleza pueda pensar la totalidad de esa naturaleza; cómo, estando destinado a morir pueda imaginarse trascender, y estando sumido en el mal, pueda aspirar a una reconciliación infinita.

Dejemos aquí esta primera frontera del hombre. ¿Qué preguntas plantea a la investigación educativa la pasmosa evolución del pensamiento? Las ciencias de la educación pretenden indagar la perfectibilidad humana; su objeto fundamental son los aprendizajes; su preocupación constante, el futuro de nuestra especie inacabada.

Es verdad que en nuestras investigaciones nos ocupan muchos problemas inmediatos, concretos e instrumentales; por arriba de ellos, conviene tomar conciencia de las grandes interrogantes que, para la educación, plantean los nuevos modos de conocer que se han desarrollado en el último siglo. El punto de partida de toda indagación sobre la educación tienen que ser las preguntas básicas

3. Czeslaw, Milosz. "El destino de la imaginación religiosa". En: Gardels, Nathan P. edit., Fin de siglo: Grandes pensadores hacen reflexiones sobre nuestro tiempo. México, MacGraw Hill, 1996.

4. Kuhn, Thomas, Las revoluciones científicas, México, PCl, 1980. Köestler, Arthur, Los somámbulos: Historia de la cambiante cosmovisión del hombre, México, Conacyt, 1981. 
de la antropología filosófica: ¿Qué sabemos sobre lo que somos? ¿Qué sobre lo que podemos ser? ¿Cuál es nuestra relación con el universo? De ahí pasaremos necesariamente a las interrogantes sobre el conocimiento: ¿Qué implicaciones tiene esta expansión del conocimiento para la formación de los seres humanos? ¿Cómo desarrollar en los educandos la actitud de asombro, la sensibilidad a la sorpresa y lograr que acepten de antemano los enigmas del mundo y los acertijos en los que estamos sumergidos? ¿En qué consiste la creatividad cognoscitiva y cómo podemos fomentarla? ¿Cuál es la naturaleza de los procesos cognoscitivos y cómo se forman y evolucionan las estructuras mentales en el niño y el joven, y ¿qué implicaciones tiene todo ello para modificar radicalmente los métodos pedagógicos y la organización de los sistemas educativos?.5.

Y ante la revolución de la informática, que complementa y potencia nuestra capacidad cognoscitiva, ¿qué prevemos, qué esperamos y qué postulamos como investigadores de la educación?

\section{LA BELLEZA}

Una segunda apertura del ser humano hacia el futuro es la búsqueda de la belleza; a través de experiencias estéticas el hombre explora y crea formas, lenguajes y significados.

El siglo que termina muestra un despliegue impresionante de creatividad artística: en arquitectura, en pintura y escultura, en música y danza, en todas las artes ha sido un siglo rico en la exploración de territorios humanos desconocidos donde nos aproximamos al espíritu que vive encadenado en nuestro interior.

Todas las artes son intentos por reducir el caos a la forma; en ellas se recurre a variados elementos -palabra, sonido, ritmo, líneas y color, materiales, expresión corporal- a través de los cuales se

5. Giordan, A. "Los nuevos modelos de aprendizaje: ¿̨ás allá del constructivismo?". en: Educación 2001, junio de 1997, pp. 40-45. 
expresa el deseo, la aspiración irrenunciable a esa plenitud inalcanzable a la que tiende nuestro ser inacabado. En la construcción de la forma intervienen ideas del mundo, mitos, preguntas sin contestación, desafíos al misterio, sentimientos, pasiones, símbolos; por la forma el artista intenta expresar las vivencias humanas de lo no dado; es la creación, en la medida en que nos es concedida.

La investigación educativa y la educación misma están en enorme deuda con esta frontera del desarrollo humano. La escuela que hemos hecho se ha centrado en el cultivo de la razón, ignorando potencialidades no estrictamente racionales para percibir la realidad, intuirla, adivinarla, recrearla y gozarla, que en la vida serán tan importantes o más que la razón. Las teorías sobre la inteligencia múltiple hoy de moda, el "conocimiento lateral" radicado en el hemisferio derecho del cerebro, no menos que los hallazgos de psicólogos y psicoanalistas, invitan a dar un lugar importante en la educación al desarrollo de estas potencialidades poco exploradas.

La escuela actual, con su disciplina y su ideal de uniformidad, descalifica los actos libres, teme lo inesperado, castiga la fantasía, el riesgo y la aventura. $\mathrm{Ha}$ arrinconado a las artes en un pequeño espacio curricular; son complemento decorativo, no experiencia esencial de formación. Para alcanzar las metas cognoscitivas que prescribe el currículum, el maestro exige disciplina, minusvalora la capacidad de invención -la suya y la del alumno-, se refugia en lo probado; las calificaciones miden sólo conocimientos y "resolución de problemas"; nadie evalúa la imaginación, el grado de libertad ni el gozo secreto del educando. El resultado es que nuestras escuelas empobrecen y reducen a lo unidimensional. Terminada su educación, quizás hasta la universidad, aquellos pocos que hayan logrado preservar alguna semilla de inconformidad se enfrentarán al reto de desaprender la escuela y recuperar su infancia.

Debiéramos introducir a los niños y jóvenes por las artes a los mundos que creamos más allá de la razón, llevarlos a relativizar el ideal de una ciencia exacta y comprobable, a cuestionar toda uni- 
dimensionalidad y a despertar sus energías latentes de percepción y sensibilidad.

¡Cuántas preguntas surgen entonces para la investigación educativa! ¿Cómo compaginar creatividad y disciplina, intuición y razón en la tarea de la escuela? ¿Cómo formar maestros a la vez rigurosos en el manejo del conocimiento y animosos para adentrarse por los territorios que bordean el desatino y la locura? ¿Cómo enseñar a pensar sin sofocar la inventiva, entregar la tradición sin lastimar la mirada limpia con que el niño renueva el mundo al mirarlo por primera vez?

\section{LA ÉTICA}

Tercera frontera de nuestra especie es la responsabilidad moral, frontera decisiva y principal porque en ella se dirime nuestra libertad, este atributo que es carga ominosa, enigma y, al parecer, signo de un destino trascendente.

En el siglo que termina el desempeño del hombre en el orden moral ha sido espléndido y trágico a la vez: decisiones criminales han desatado guerras y violencias planetarias y exterminado a millones de seres humanos sin otro motivo que el ansia de dominio o de riqueza, el desprecio al débil o el odio racial; y en el otro extremo ha habido avances que reaniman la confianza en que algún día aprenderemos, como humanidad, a conquistar la paz basada en la justicia, a respetarnos universalmente, a ser solidarios y sensatos, y a asumir la responsabilidad del universo, en la medida en que nos compete. Hoy es claro, como nunca antes, que ante los riesgos que nos acechan, sólo nuestra conciencia moral nos salvará.

Se han ensanchado los límites de nuestra responsabilidad. La humanidad se encuentra perpleja, como aprendiz de brujo, ante sus propios avances; no logra definir comportamientos mínimamente responsables ante el uso de la energía atómica, la conquista del espacio, las amenazas a los recursos naturales y al medio am- 
biente 0 las técnicas que manipulan peligrosamente la vida humana en sus fuentes; perpleja también ante las injusticia planetarias, fruto de un modelo de desarrollo impulsado por el lucro en vez del bienestar compartido por todos; perpleja ante el uso del poder en contra de la dignidad y de los derechos humanos de gran parte de los hombres. No tenemos una ética universal a la altura de estos retos ni sabemos cómo fundamentarla. Ésta es sin duda la frontera más arriesgada del futuro de la especie.

Los problemas éticos están en el corazón de la educación; debieran estarlo también en el corazón de nuestra investigación. Todo investigador de la educación es, en alguna medida, filósofo del hombre; no le son ajenas las preguntas sobre sus valores, su destino o el ejercicio de su libertad. Hoy nos preguntamos, por ejemplo, por los fundamentos de una ética universal para el siglo XXI. Del diálogo internacional van surgiendo varios fundamentos válidos para establecer los necesarios consensos, por arribas de culturas, iglesias o ideologías. El fundamento principal que emerge como aceptado por todos es el prójimo, el "otro" - o en frase de Octavio Paz, "los otros todos que nosotros somos"-; porque el "otro que está en nosotros" es condición fundadora de toda moral humana; en su alteridad encontramos la reciprocidad que interpela nuestra responsabilidad. Quienes no puedan amar al prójimo como a sí mismos, diría Paul Ricoeur, aceptarán al menos amarse a sí mismos como al prójimo, y en la salvaguarda del propio yo encontrarán el fundamento de una responsabilidad hacia quien refleja ese yo.

Tres aspectos del "otro" parecen tener especial relevancia para fundar una ética universal: uno, la vulnerabilidad que nos es común a todos y nos hermana (¿quién está exento de la vulnerabilidad del más vulnerable?); segundo, el prójimo es sobre todos los prójimos futurơs, los aún no nacidos, de los que somos responsables desde nuestro presente (¿quién puede sentirse desligado de responsabilidades hacia los hombres por venir y hacia la vida en todas sus manifestaciones?); y tercero, la dignidad de la persona 
humana, por cuanto percibimos y sentimos que ninguna persona -por estar abierta hacia algo más alto y más grande que ella mismapuede ser sometida o instrumentalizada, y tiene por ello algo de sagrado y absoluto.

Junto a esta cuestión de la posibilidad y fundamento de una ética universal a la altura del futuro, surgen para la investigación educativa otras muchas: ¿cómo educar para una convivencia justa y armoniosa, que sea el sustento de una paz permanente? ¿Cómo hacer que los educandos acepten y asimilen realmente la igualdad esencial de todos los seres humanos y los respeten como sujetos de derechos humanos inviolables? Y la pregunta crucial de toda educación: ¿̨cómo formar la libertad responsable?

Dos características deberá tener la ética del mundo que viene: concebirse planetariamente, por arriba de fronteras nacionales y espacios geopolíticos, porque la humanidad es cada vez más "una", y estar a la altura de los avances de la ciencia que sacuden cada vez más los referentes tradicionalmente establecidos. Relacionar estas graves cuestiones con la práctica educativa cotidiana y lograr que la escuela se transforme en el sitio donde las nuevas generaciones aprendan a tomar decisiones de conciencia, justas y libres, abre un inmenso horizonte a nuestra tarea de investigadores.

\section{Conclusión: LA UTOPÍA}

He ahí, pues, nuestra especie en devenir: 6,000 millones de seres humanos en marcha -cabeza, tronco y extremidades y un extraño anhelo de alcanzar lo absoluto-, en marcha sin tregua, persiguiendo su propia sombra, encorvados sobre sus pequeñas, cotidianas ocupaciones y preocupaciones; parecen sonámbulos enajenados, que sólo en algunos momentos excepcionales levantan la frente y

6. Eco. Humberto y Martini. Carlo. ¿En qué creen los que no creen?. traducción y prólogo de Esther Cohen. México. Taurus, 1997.Levine y Lezotte. op cit. 
se advierte en sus ojos el fulgor de su destino. Son los momentos en que se proclaman los derechos humanos, triunfa alguna revolución o se acepta la democracia con las magnanimidades que supone.

Para despertarlos es indispensable sacudirlos, hasta que tomen conciencia de que llevan dentro la semilla del deseo, del aquél del que brota la utopía. Pues la utopía nos acompaña en nuestro azaroso devenir para recordarnos que somos especie inacabada en camino hacia un futuro superior. La triple apertura que hemos comentado -hacia el pensamiento que se supera a sí mismo, hacia la belleza que nos invita y seduce, hacia la plenitud de nuestra libertad responsable- converge en esta capacidad inherente y necesaria de crear y recrear continuamente "visiones desiderativas" del mundo. Sin utopía no se explica ni el avance del pensamiento científico, ni la historia de las ideas y de los mitos, ni el desarrollo de la técnica; ella es el motor que ha impulsado las artes, la literatura y la arquitectura con todas sus audacias, los descubrimientos geográficos, la exploración del espacio, y, por supuesto, todas las religiones. El hombre sin deseo no sería hombre; la educación sin utopía sería simplemente inconcebible.

Las utopías, explícitas o implícitas, son necesarias en la investigación social; no son un falseamiento de la realidad sino recurso necesario para explorar sus posibilidades radicales; prolongan las líneas de lo real hasta el punto de poner de manifiesto la banalidad de sus actuales límites o de descubrir sus virtualidades escondidas; develan el fondo decisivo de lo real y orientan el conocimiento hacia lo realmente relevante. En ellas se cruza nuestra esencia inacabada con lo inacabado del mundo; de ambas posibilidades, exploradas por el deseo, surgen nuevos horizontes que permiten a la especie seguir avanzando en su penosa autodefinición. El pensamiento utópico cumple un cometido social, expresa tendencias reprimidas o germinales que reclaman ser realizadas, define emocionalmente la satisfacción de necesidades aún no proferidas, eliminando los deseos banales que hay que olvidar y ahondando los deseos profun- 
dos que hay que alcanzar. Esas islas imaginarias en que se realiza la felicidad son parte de nuestro universo interior y atraen las brújulas del desarrollo humano del futuro; por esto decía Oscar Wilde que "un mapamundi sin el país Utopía no merecería siquiera una mirada". Por esto aceptamos -la frase es de Bloch-que "la razón no puede prosperar sin esperanza, ni la esperanza expresarse sin la razón."

No es posible pensar la educación sin poner en movimiento el deseo y la fantasía y sin que surjan de las sombras los grandes mitos de una añoranza inveterada: el paraíso perdido, el Éxodo hacia la Tierra Prometida, el Prometeo que roba el fuego a los dioses y por ello es encadenado, la edad de oro, el estado de naturaleza, el Dorado... o, en las culturas indígenas el reino de la flor y el canto donde se enjugan todas las lágrimas -reflejos todos ellos, quizás, de un Reino de Dios anhelado, a la vez futuro y actuante en la historia presente, en cuya búsqueda persistimos obstinados.

La utopía, además, abre las puertas al reino de la gratitud, donde damos sin recibir, nos abandonamos a la piedad y encontramos la reconciliación.

Las grandes utopías han estado siempre suscitadas por su circunstancia histórica. Platón en La República, San Agustín en La Ciudad de Dios, Joaquín de Fiora y otros milenaristas, acompañados de los albigenses, hussitas y anabaptistas, Tomás Moro y Erasmo con sus Utopías, Campanella con La Ciudad del Sol, Bacon con la Nova Atlantis, Owen, Saint-Simon y Fourier con sus visiones sociales ideales, (también los sueños que empezaron a ser realidad, como las misiones jesuitas del Paraguay o, entre nosotros, la organización social de Don Vasco), todas las utopías han respondido a los cambios y agitaciones de su momento. Si el pensamiento utópico es respuesta a coyunturas en las que se atisba, como por rendijas, el

7. Bloch, Ernst. El principio esperanza. vol. II. Biblioteca Filosófica. Madrid. Aguilar, 1980, p. 1. 
futuro, ¿qué utopía será la que hoy corresponda a la enorme plasticidad del mundo en este fin de siglo? ¿Qué desmesura del deseo nos es hoy necesaria para proteger la libertad de los seres humanos futuros?

Dejemos esta pregunta abierta. 중 